\title{
sciendo
}

\author{
RESEARCH PAPERS FACULTY OF MATERIALS \\ SCIENCE AND TECHNOLOGY IN TRNAVA \\ SLOVAK UNIVERSITY OF TECHNOLOGY \\ IN BRATISLAVA
}

2020, Volume 28, Number 46

DOI 10.2478/rput-2020-0005

\section{COVID-19 AND INDUSTRY 4.0}

\author{
György CZIFRA ${ }^{1}$, Zsolt MOLNÁR ${ }^{2}$ \\ ${ }^{1}$ OBUDA UNIVERSITY, DONAT BANKI, \\ FACULTY OF MECHANICAL AND SAFETY ENGINEERING, \\ H 1081 BUDAPEST, NEPSZINHAZ U. 8, \\ ${ }^{2}$ GRAPHIT KFT., 1027 BUDAPEST, MEDVE UTCA 17 \\ e-mail: czifra.gyorgy@bgk.uni-obuda.hu,Zsolt.Molnar@graphit.hu \\ Received 15 April 2020, accepted 28 April 2020, published 25 June 2020
}

\begin{abstract}
Nowadays, the whole world is talking about the corona virus. The world economy has slowed down, large businesses and small businesses as well as private ones struggle to survive. The current situation will affect the lives of all of us. How can we handle this situation? How does business flexibility help us? How can we use modern technology to restore the functioning of the economy? How can losses be reduced? In this paper, we are trying to find answers to these issues. To search for answers, we used the publications of renowned experts. We summarized the overview of their views of this important issue.
\end{abstract}

\section{Key words}

Corona, covid-19, Industry 4.0, economy, business, flexibility, digital manufacturing

\section{FLEXIBILITY AND THE MARKET}

This section was compiled of on the materials in [1].

Flexibility is the goal of many manufacturers to gain or maintain market leadership in their industry. Organizations that were able to demonstrate flexibility were asserted without problems on the market.

Flexibility can be understood as quick adaptation. We are talking about creating a smooth flow of goods and services from demand to delivery. True flexibility allows manufacturers to quickly meet market demands. It is a replacement of a rigid and static operating model with a high level of control and sensitivity that has never been possible before.

Flexibility is more than just technology. Technology is in the focus of transformation and is constantly propelling and enabling new ways of innovation. However, technology alone cannot bring change quickly without the support of a flexible organizational environment. For this reason, we need to look at the background of processes to identify areas that allow flexible operations in organizations and manufacturing companies.

The starting point for increasing flexibility is to identify where there may be potential obstacles and barriers. Exploring these options requires that we conduct a comprehensive 
review of each area that contributes to meeting the needs of the market. Such a procedure makes it possible to resolve inconsistencies and better allocate resources to continually improve the organization.

In cooperation with customers, it is possible to start from the following six areas.

Technology

Intelligent systems can provide greater flexibility at the technical level. For many years, production has been based on static off-line production lines controlled by systems of often impractical operating technologies. Now in the current era of digitization, manufacturers can combine control and information systems to collect and analyze data to the smallest detail. This analysis, together with feedback, can be used to adapt and refine operations during production system operation.

\section{Skills}

One of the basic mistakes that a manufacturer can make is to focus only on technology and ignore the human element. Qualified operators, engineers, and analysts are an important part of the personnel needed for flexible production. Flexibility options are limited if workers are unable to use their high-level skills. The company's specialization and commitment to staff qualifications, therefore, support a flexible approach by ensuring that technological change cooperates with the human resources used.

\section{Powerful support}

The decision-making bodies within the company structure should also have flexibility. The decision to produce a new product based on current customer requirements or to discontinue the production of a profitable product based on changing market requirements needs to be made very quickly and in a coordinated way. The presence of powerful ingredients with a broad representation of business units supported by clear rules of decision-making can greatly increase the probability of success of the innovation project.

\section{Consumption models}

Over the past few years, the main trend has been a shift towards consumer models based on subscription services. Instead of a capital-intensive model, online services and online applications are currently in use. Ownership of physical machines is a huge obligation, and the manufacturer has to invest in dead assets throughout his lifetime. For greater flexibility, manufacturers are now adopting a service-based approach, not a machine-owning approach. This helps to increase the efficiency of a business with an increased ability to upgrade and adapt to requirements based on rapidly changing market conditions.

\section{Understanding the market}

The last area is about understanding our customers. In many organizations, the market is usually seen as a hidden function that is responsible for increasing sales without directly affecting production. This approach is no longer applicable. Now, for a business to be successful, sales and marketing must be directly related to production. To meet customer requirements, we need to understand what the customer wants, what product the customer wants, and therefore we must adapt production constantly. This is true not only for the features and quality of the product but also extends to issues relating to ethical and sustainable practices that are increasingly important requirements from customers.

\section{Flexible growth}

Removing rigidities in each of the key areas can help to create a solid foundation on which to build and work. New modern technologies based on simulation programs support the design of the solution and the search for answers to the questions. Using functional simulation models, it is possible to design and initiate concepts that allow testing of proposed procedures in a computer environment. After successful simulation tests, it is safer to make initial investments and allocate resources to implement new procedures and test them live for several months and 
monitor the performance of the new solution. After proving the functionality and efficiency of the new concept, it is possible to introduce a new method across the entire production.

\section{HOW WILL CORONAVIRUS AFFECT THE WORLD ECONOMY IN 2020?}

This section was based on the Business Insider Intelligence analyses [2].

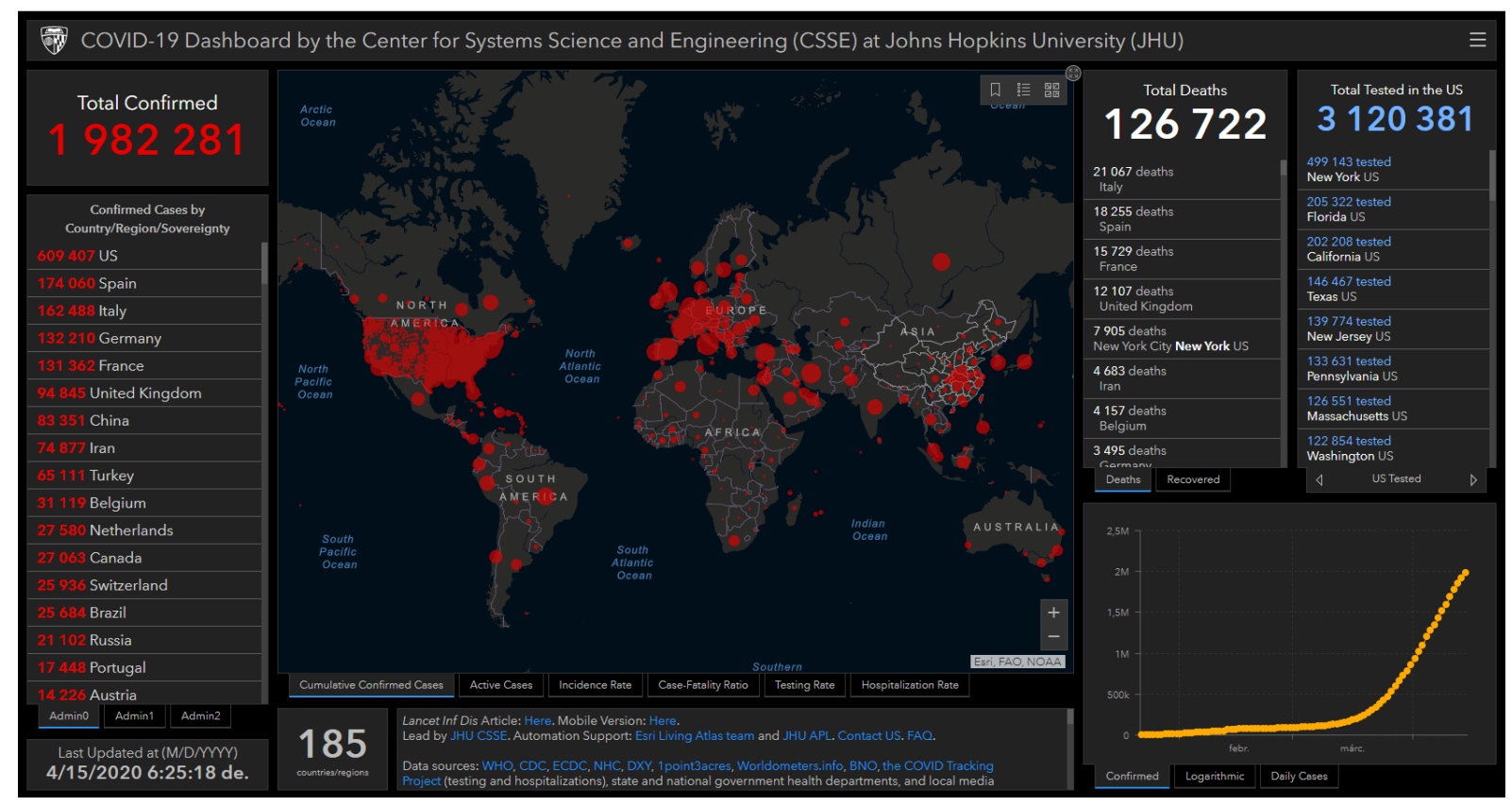

Figure 1 Situation - Covid 19 to day 15/04/2020 [4]

The initial outbreak of coronavirus appeared in China. However, the outbreak has grown into a global pandemic and has cut global supply chains. Currently (15.04.2020), 1982281 worldwide confirmed cases and 126722 deaths and 487471 recovered (Coronavirus COVID19 Global Cases by the Center for Systems Science and Engineering (CSSE) at Johns Hopkins University (JHU). It affects 185 countries and regions. Many meetings, congresses, and exhibitions had to be canceled as a result of restrictive measures. Nowadays many companies are moving to work remotely, the world industry is facing big problems due to delayed responses and unusable production capacities due to production stoppage and transport. [4]

But the telecom and technology industry has found a way to help companies keep people safe and healthy. They help companies to organize and conduct videoconferences as much as possible, freeing up resources and capacity for telecommunications technologies. They help governments disseminate accurate information about the virus to citizens and seek intelligent technologies to combat the pandemic: (https://www.bloomberg.com/news/articles/2020-0325/netflix-reduces-video-quality-in-more-countries-to-handle-surge)

Here are some ways that coronavirus can have an impact on the world economy.

\section{Disruption of supply chains.}

The core of the pandemic was in the region of China and was a hard hit. Many people became ill with this disease and many were forced to quarantine. This led to a partial and descendant cessation of production in factories and factories. These companies produced for major technology companies. For example, Apple has seen a shortage of iPhone components 
as a result of the fact that Foxconn's main manufacturer stopped a large part of its production in China.

According to estimates of Apple's Ming-Chi Kuo analyst quoted by MacRumors, this will ultimately lead to a significant reduction in iPhone deliveries of up to $10 \%$ in the first quarter. And while companies have prepared replacement plans to increase production in a non-affected region, the rapid spread of coronavirus worldwide makes it impossible to move production to areas less affected. The dynamics and resources of the Chinese economy will not be easily recoverable despite initiatives by the Chinese government that is preparing to invest billions in advanced manufacturing sectors, including telecommunications equipment and semiconductors.

\section{Cancellation of technical and technological conferences}

The Mobile World Congress (MWC), scheduled to take place on February 24-27 in Barcelona, was canceled due to virus concerns. MWC is the cornerstone of connectivity, bringing together the most important companies in the space, sharing innovations and creating new business partnerships. Several companies have rescheduled the events they planned for MWC, but the continued presence of the coronavirus has led others to abolish them completely.

Google is organizing its Google Cloud Next event as an online conference, and IBM also had to cancel a developer conference that hosted over 30,000 attendees last year. PredictHQ estimates quoted by Recode said that the cancellation of major technology conferences and meetings caused direct economic losses of more than $\$ 1$ billion.

Online conference alternatives have helped reduce the impact of canceled conferences, but the technology industry is likely to suffer from a downturn in innovation processes as a result of lost business opportunities for potential partners. Conference participants have limited opportunities to make contacts through live broadcasts as opposed to face-to-face meetings at events. While it is difficult to quantify the financial value of these face-to-face or informal meetings, the effects will undoubtedly be felt in all affected sectors.

\section{An increasing need for remote interactions}

The growing need for rapid and secure communication and the transfer of enormous amounts of data due to the isolation of humans due to the coronavirus pandemic has highlighted the need for 5G technology. This fact potentially speeds up acceptance in the long run.

Extremely high transmission speed over $5 \mathrm{G}$, almost instantaneous response and increased link density make it the basis for remote connections. These are key features that have become the main goals of many organizations and businesses. The spread of the virus causes caution in personal contact, restricting the movement of people. During a pandemic, two key areas telehealth and teleconferencing - are becoming critical to business operations, and we believe that increased dependence on these areas will help strengthen the appeal of 5G:

\section{Telehealth}

The technical superiority of the new standard allows doctors to diagnose, treat and care for patients without being physically present. We have seen such cases of using $5 \mathrm{G}$ to fight coronaviruses in China: In January, ZTE and China Telecom designed a 5G-based system that allows remote consultation and diagnosis of the virus by connecting doctors in a Western China hospital to 27 hospitals with infected patients. Given the ability of 5G to extend the transfer of expertise and services offered by hospitals at times of increased need, more hospitals are likely to seek to take advantage of the new $5 \mathrm{G}$ standard.

Teleconferencing: Many employers have put in place enterprise teleconferencing tools such as Microsoft, Google Hangouts and Zoom - and employees have gone to the home office to work remotely to ensure public and private health. Employers are likely to use such tools 
during coronavirus pandemics to strengthen their efforts to introduce $5 \mathrm{G}$ technology in homes - and offices. Businesses will recognize the value that teleconferencing tools offer. The 5G connection will be able to provide continuous real-time communication, which today is not possible with most cable connections.

\section{The use of virtual reality (VR) in businesses}

The expansion of the coronavirus has caused large technology companies such as Apple, Google, and Microsoft as well as smaller companies to choose to offer employees the opportunity to work from home - home office companies like Amazon and other companies have limited their employees' travel to affected areas like China, But Italy, the US, now virtually all over the world. It is the safest solution during a pandemic, but it makes cooperation difficult and practical training impossible. When these problems become critical, businesses will look for ways to avoid interrupting their work. One possible solution is likely to be virtual reality or augmented reality.

Companies have already used the $\mathrm{CoR}$ as a tool to improve staff training, but a coronavirus could provide an impetus for technology implementation. Nearly half (49\%) of business respondents, according to a Perkins Coie survey, try to use VR and other augmented reality tools to create realistic training conditions. If employees are at home, they can maintain their skills with courses previously only available in the workplace. For example, a technician can make repairs to an industrial facility without leaving his home. Also, a wider range of meetings can be held through the CoR as workers can better view and share complex ideas such as prototype designs - $20 \%$ of employees identify communication and collaboration as their biggest match with telework.

\section{Investments in smart city solutions will grow}

Cities around the world have used smart city technology to try to mitigate the effects of coronavirus. Police in China uses robots with thermal sensors to identify people in public who have a fever. The South Korean government has developed an application for smartphones that allows people in quarantine to keep in touch with healthcare professionals. This solution allows them to monitor patients' health and ask questions about their condition. The Australian government has launched a chatbot to answer citizens' questions and suppress the spread of misinformation.

These solutions belong to the field of smart cities, which in times of crisis proves that investing in smart solutions in cities is justified. Most smart city solutions are designed to support everyday city operations. However, this core infrastructure - be it city-wide connectivity, surveillance systems or communication platforms for citizens - can be tailored to meet the needs of a government in times of crisis like a pandemic. Business Insider Intelligence estimates that smart city investments will reach $\$ 295$ billion by 2025 , from $\$ 131$ billion in 2020. If smart city solutions prove to be an effective tool to alleviate a pandemic, governments may be more inclined to make further investments and accelerate thereby introducing smart solutions.

The past and coming weeks have brought and will bring, a new level of uncertainty to the lives of manufacturing and logistics companies, that has never been seen before in the history of modern manufacturing. Logistics and manufacturing processes were damaged at the same time, the first due to supply chain insecurity and the second due to employee disruption. While the office processes of schools, education, and companies have taken a huge step in digitizing their processes in just a few days, in the case of production and real productive work the vulnerability and inflexibility of the processes and systems have become visible. Despite all good intentions, manufacturing cannot be done from a "home office". 


\section{INDUSTRY 4.0 AND COVID-19 [3]}

Prior to the covid-19 crisis, I4.0 business leaders were focused on gaining competitive advantage, increasing productivity, reducing costs, sustainability, innovation. The main objective was to improve the functioning of well-functioning businesses.

Many manufacturers now focus primarily on survival and on reducing the damage caused by a pandemic. The financial crisis for producers is already leading to a significant reduction in non-essential expenditure and less needed investment. Many of the Industry 4.0 investments that have been planned are currently being canceled, categorized as unnecessary investments.

The situation raises several questions:

Is I4.0 what leading manufacturers should think about?

Is I4.0 still relevant?

If I4.0 is relevant, what role will it play in the future?

The short answer for all questions is yes. We think that the I4.0 is in fact much more important than before.

Most manufacturers have the following priorities today: Phase 1 - Survival; Phase 2 Recovery; Phase 3 - Renewed work in a new post-crisis life.

The goal of all manufacturers is to get to Phase 3 as soon as possible at the lowest price. When we define for the Phase 3 an Operating Model, we need to consider the experiences of the crisis period and try to build a more resistant and agile business. We are looking answers to some basic questions: Where were the weaknesses? Where did they make costly decisions and why? What would help?

The main point will be that the systems and processes used so far were not suitable. It is clear from the events that are happening before us that one of the main weaknesses is the lack of real-time transparency throughout the enterprise. There is a lack of transparency that is necessary to support critical business decisions.

The role of Industry 4.0 in the future:

- Help ensure that more businesses survive

- Shorten the recovery phase and help businesses return to normal business as quickly as possible is

- Provide a platform to develop new, more resilient businesses in the medium and long term.

Here are just a few examples:

- Visibility of real-time availability of raw materials, finished products, people and property

- Using artificial intelligence and machine learning to continually review and reschedule activities

- Robotic Process Automation (RPA) to support labor intensive activities without added value

- Utilize mobile technology and augmented / virtual reality to enable workers to more easily perform tasks for which they have not been trained. This could help with skills shortages due to isolation or restart of production technologies with digital twins and remote support from OEMs would improve resource availability

- The same technologies are designed to allow remote and virtual work to help solve the problem of locking and social distancing

- 3D printing of spare parts stuck in the supply chain

- Use of autonomous electric vehicles and AGVs to reduce dependence on people and to further help with social distance. 


\section{CONTINUITY AND SAFETY}

Companies need to develop solutions that, in addition to ensuring the continuity of the supply chain, also guarantee the safety of those working in production.

If the present situation has a positive effect, it is that digitalization is gaining in value and becoming more important in the life of companies. In the case of a company, however, this does not happen in a few days.

Digitization has become one of the most important tools for transparency and improvement of processes in recent years. However, standardization is seriously compromised when conditions change to such an extent that all organizations switch to "firefighting" mode and always focus on solving the given problem with agile methods and move on to the next task. And "firefighting" means decisions, and in that case, it does matter how much information is available to decide. And industrial digitization and industrial digitalization solutions have, and will, play a key role in this.

There are two main areas of the industrial software solutions which can give high-level support to the decision-makers on every level of a company. The discrete event simulation is key to creating, planning and analyzing the processes, while advanced production scheduling can help to make the right decisions in the level of the actual production.

The main reasons for the manufacturing uncertainty are:

- Customer-related parameters: unreliable forecasts, last-minute design changes

- Manufacturing related parameters: machine and resource failures and breakdowns, resource capacity, technology constraints, lack of communication between departments (manufacturing planning and production and logistics), missing or inaccurate base data for operational planning

- Supply chain related parameters: lead time of the purchase orders, issues with the transportation of the material, unplannable issues at border controls and border control procedures
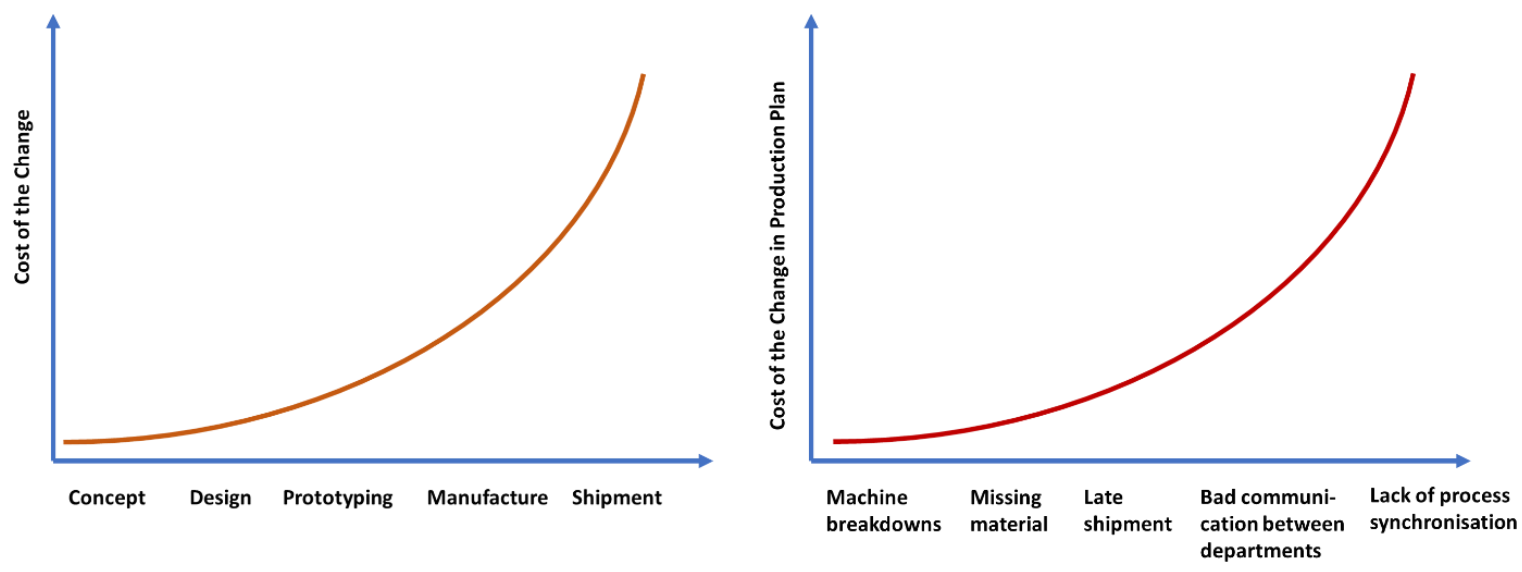

Figure 1 The cost of design change during manufacturing and the cost of inadequate planning during manufacturing have a similar characteristic 
It is a well-known fact that the later a design problem is discovered, the greater the impact on cost during the manufacture or launch of the product (Fig. 2). In our experience, there are a couple of features in production design that can cause similar losses during production. Of these, it is perhaps surprising that downtime has the smallest role, although manufacturing companies often consider this to be the most important. Yet the problems resulting from desynchronization and lack of communication cost much more.

The old Excel-based solution cannot compete in describing dynamically changing manufacturing processes. The new evolving tools, like manufacturing simulation and production scheduling, are powerful ways to support decision-making processes (Fig. 3).

Regarding digital manufacturing, there are several areas that we will have to do. One, perhaps the most basic, is the design of layouts related to production processes. The end of the era of production cells crammed into spaces as small as possible, and workers very close to each other. In the case of a modern cell, distance of 2 meters between workers will be ensured. The cells will have adequate ventilation and, if necessary, separate safety walls between the workers. The mode of material transfer will also change a lot, the role of manual material transfer will decrease, and the role of non-contact automated material transfer between cell stations will also increase. It can also be seen from these that the concept and design rules of a safe workplace will undergo significant change.

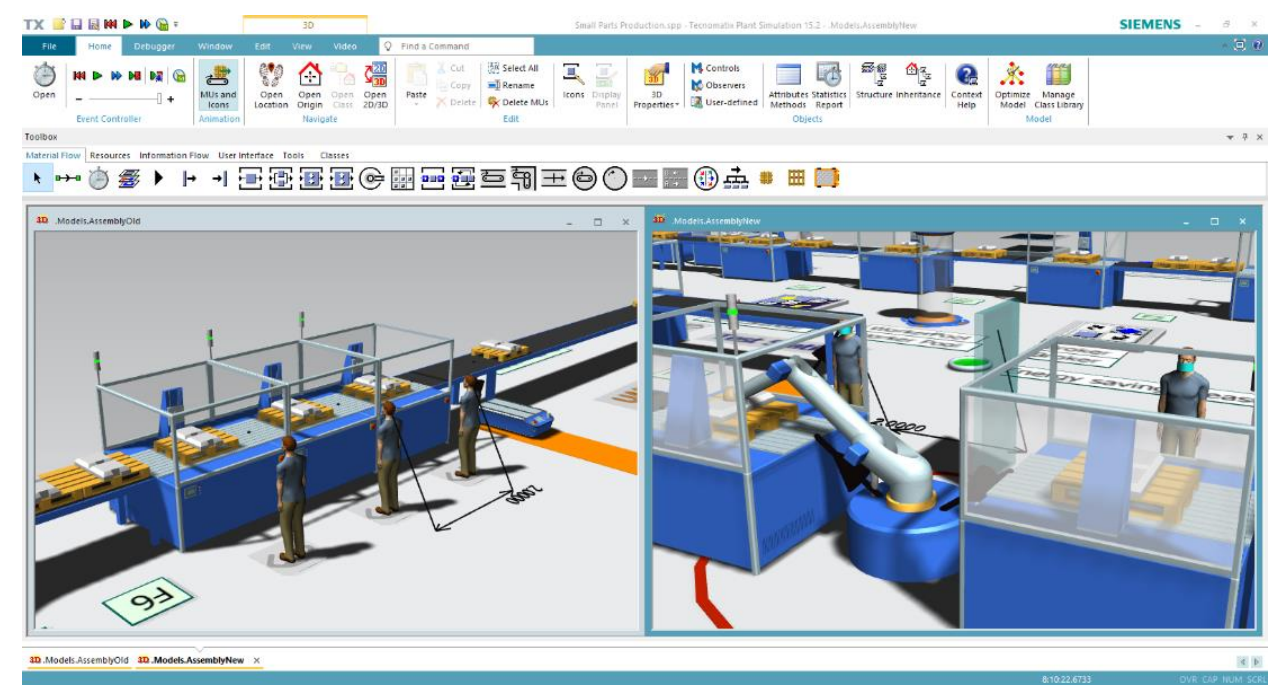

Figure 2 Manual production line and its redesigned version from the employee's safety point of view (face mask, separating wall, no-touch material transfer)

The other key area is to make processes more flexible. I think the future belongs to flexible production areas, where it is possible to produce a book in one week or even a health mask in another. This may sound very futuristic now, but 3D printing, for example, could be the basis for technologies that offer such flexibility. The production and logistics process simulation tools can help in the virtual testing of such improvements and initiatives.

At first look, it means that automation will be more and more important. But it's only partially true. On the one hand, in a similar case, the operation of factories is much more sustainable with automated lines and systems, but even if our lines are automated, if we cannot provide the raw material, the supply chain will not work. What is good news, however, is that most companies would be able to respond more flexibly to changing circumstances, be it a change in the number of employees or a disruption in the supply of raw materials.

Advanced planning and scheduling are for this purpose. It gives the procurement, in the hands of the production planner, a tool with which, based on the available information, it is 
possible to create a consistency between the state of production and the needs and forecasts, taking into account deliveries, the number of employees and other technological conditions.

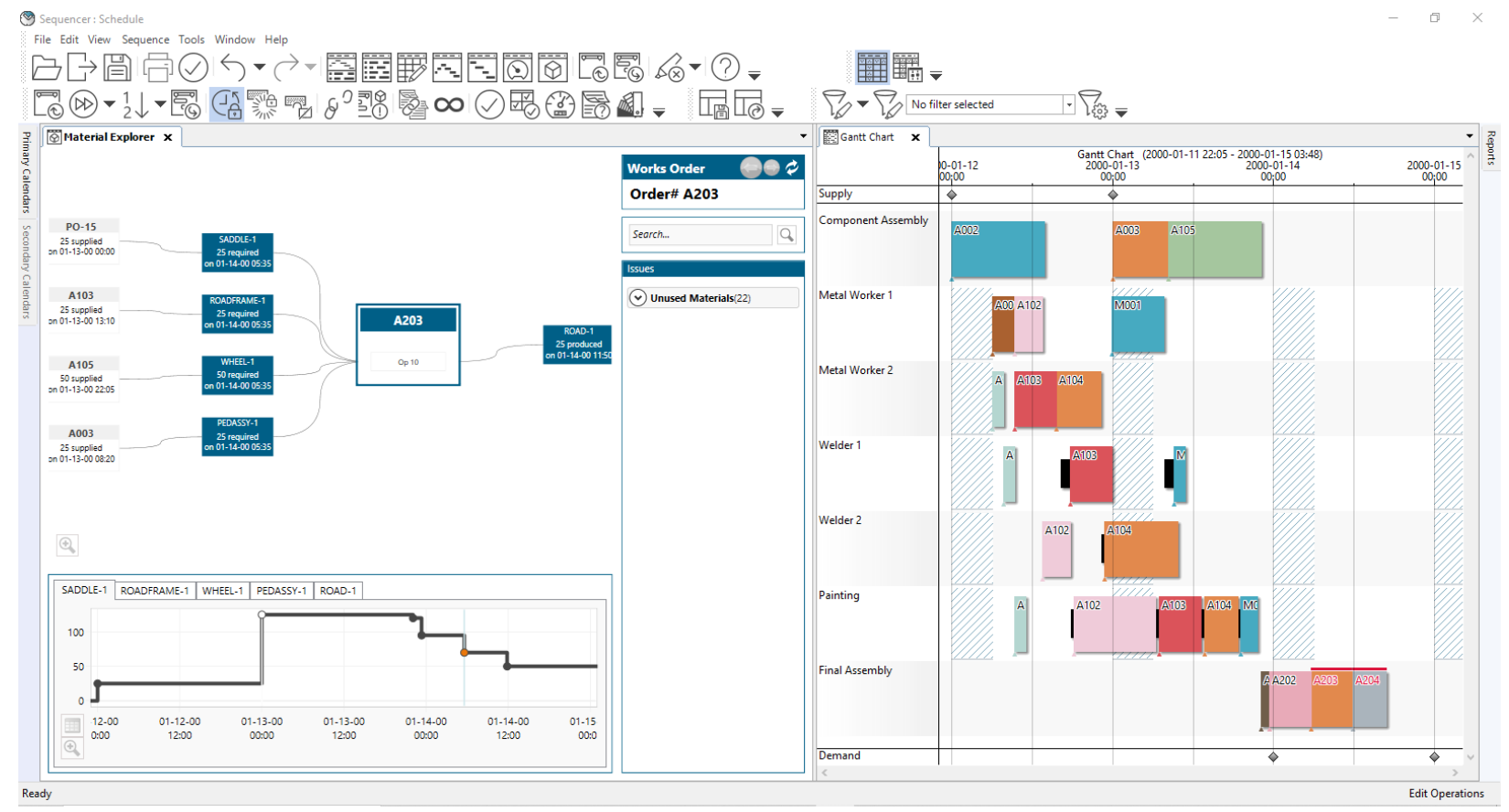

Figure 3 Advanced scheduling helps to continuously align demand, forecasts, sourcing and production capacity

From process testing and stability, there is a serious opportunity to combine discrete simulation and production scheduling. In this case, the simulation acts as a digital twin pair of real production, simulating what happens in production over time. Using the production schedule, process stability and response time, changes can also be tested on the digital twin pair (Fig. 4). This allows for risk-based scheduling that can tell you what the probability of a production outcome is for a given problem.

We can say that it is no longer possible to prepare for the current crisis, but we need to learn from it and be prepared for the company's immune system to be stronger in the event of the next crisis. After the restart, domestic manufacturing companies, whether small family businesses or large multinational manufacturing companies, need to be prepared for this.

\section{CONCLUSION}

This year's coronavirus epidemic is expected to lead to the biggest economic downturn in European history since World War II, as well as mass unemployment and waves of bankruptcy.

The European Union (EU) economy is expected to follow a V-shaped path, with a sharp rise towards the end of this year, but this will not fully offset the losses. The performance of the European economy could reach the 2019 level in 2022. Gross domestic product (GDP) will continue to decline this year, surpassing the biggest decline in 2009. The lowest point may come in May, followed by stabilization and recovery in the second half of the year. The uncertainty of the forecast is higher than usual, the development of the processes depends on whether the epidemic can be managed and to what extent the restrictions can be eased. Despite government rescue programs, a wave of bankruptcies is expected in several sectors and the number of registered unemployed could increase tremendously by the end of the year. 
In this situation, we have the opportunity to explore the potential of Industry 4.0 and introduce solutions that offer jobs and opportunities to transform and digitize industry, commerce and logistics by creating new jobs.

In the end, there is an interesting conclusion by John Robinson:

"...the key to successful digital transformation was not technology but collaboration..." (John Robinson, Strategic Client Advisor, Digital Supply Chain at SAP)

\section{References}

[1] Flexible Manufacturing: Adapting Quickly to Changing Markets and Events on http://emag.directindustry.com/flexible-manufacturing-adapting-quickly-to-changing-marketsand-events/ seen: 15.04.2020

[2] Five ways the coronavirus will affect the connectivity and tech industry in 2020 on https://www.businessinsider.com/five-ways-coronavirus-will-affect-the-connectivity-techindustry-2020, (Business Insider Intelligence 18 Mar 2020, 15:45 o'clock), seen: 15.04.2020

[3] What is the future for Industry 4.0 in the post Covid-19 paradigm? on https://www.themanufacturer.com/articles/what-is-the-future-for-industry-4-0-in-the-post-covid19-paradigm/ seen: 15.04 .2020

[4] COVID-19 Dashboard by the Center for Systems Science and Engineering (CSSE) at Johns Hopkins University (JHU) on https://www.arcgis.com/apps/opsdashboard/index.html\#/bda7594740fd40299423467b48e9ecf6

[5] OKTATÁSI PORTÁL on http://edu.graphit.hu/ seen: 15.04.2020

[6] Projected coronavirus (COVID-19) impact index by industry and dimension on https://www.statista.com/statistics/1106302/coronavirus-impact-index-by-industry-2020/ seen: 15.04 .2020

[7] Industry 4.0 Adoption 2020 - who is ahead? On https://iot-analytics.com/industry-4-0-adoption2020-who-is-ahead/ seen: 15.04 .2020

[8] Simulate logistics and material flow for improved system performance on https://www.plm.automation.siemens.com/global/en/products/tecnomatix/logistics-material-flowsimulation.html seen: 12.04 .2020

[9] Industry 4.0 in the time of the Coronavirus on https://www.paperfirst.info/industry-4-0-in-the-timeof-the-coronavirus/ seen: 10.04.2020

[10] Fernandes, Nuno, Economic Effects of Coronavirus Outbreak (COVID-19) on the World Economy (March 22, 2020). Available at SSRN: https://ssrn.com/abstract=3557504 or http://dx.doi.org/10.2139/ssrn.3557504

\section{ORCID}

György Czifra 0000-0002-4758-0773 